Journal of Molecular Structure, 39 (1977) 253-262

() Elsevier Scientific Publishing Company, Amsterdam - Printed in The Netherlands

\title{
ELECTRON DIFFRACTION STUDY OF THE MOLECULAR STRUCTURE OF BIS(TRIFLUOROMETHYL)PEROXIDE
}

\author{
C. J. MARSDEN* and L. S. BARTELL**
}

Department of Chemistry, University of Michigan, Ann Arbor, Michigan 48109 (USA)

F.P. DIODATI

Facultad de Ingenieria, Universidad de Buenos Aires, Buenos Aires (Argentina)

(Received 11 January 1977)

\begin{abstract}
The following structural parameters and estimated standard deviations ( $3 \sigma$ ) have been found for $\left(\mathrm{CF}_{3} \mathrm{O}\right)_{2}$ : $r_{\mathrm{z}}(\mathrm{O}-\mathrm{O})=1.419 \pm 0.020 \mathrm{~A}, r_{\mathrm{g}}(\mathrm{C}-\mathrm{O})=1.399 \pm 0.009 \mathrm{~A}, r_{\mathrm{g}}(\mathrm{C}-\mathrm{F})=1.320 \pm 0.003 \mathrm{~A}$, $\angle(C-O-O)=107.2 \pm 1.2^{\circ}, \angle(F-C-F)=109.0 \pm 0.5^{\circ}$, and dihedral angle $(C-O-O-C)$ $=123.3 \pm 4.0^{\circ} . \mathrm{CF}_{3}$ groups are in or close to staggered conformations; their axes are tilted by $2.7 \pm 1.2^{\circ}$ away from the $\mathrm{C}-\mathrm{O}$ bonds in the usual manner. Shrinkage corrections and amplitudes of vibration, with which measured amplitudes agreed satisfactorily, were calculated from an approximate valence force field. No evidence was found to indicate that the assumptions of $C_{2}$ molecular symmetry and local $C_{3 v}$ symmetry for the $\mathrm{CF}_{3}$ groups were unduly restrictive.
\end{abstract}

\section{INTRODUCTION}

Fluorocarbons and their derivatives display chemical and physical properties which are in general strikingly different from those of their hydrocarbon counterparts. We are interested in ascertaining the extent to which such differences are reflected in, or caused by, differences in molecular structure, and in the nature of the electronic and steric forces which determine both. Bis(trifluoromethyl)peroxide has been studied by vibrational spectroscopy [1], but no structural information is available. We present herein the results of our electron diffraction investigation.

\section{EXPERIMENTAL}

A sample of $\left(\mathrm{CF}_{3} \mathrm{O}\right)_{2}$ was purchased from PCR, Inc., and used as received. No impurities were revealed by g.l.c. analysis. Electron diffraction data were recor̃ded on $4 \times 5$ in. Kodak Electron Image Plates, using the unit at the

\footnotetext{
*Present address, Department of Chemistry, The.University, Southampton SO9 5NH (England).

* Author to whom correspondence should be addresed.
} 
TABLE 1

Experimental conditions under which diffraction patterns of $\mathrm{CF}_{3} \mathrm{OOCF}$, were recorded

\begin{tabular}{llll}
\hline & I & II & III \\
\hline Camera distance (cm) & 20.479 & 10.325 & 6.035 \\
Sector (radius, cm) & $r^{3}, 4.8$ & $r^{3}, 4.8$ & $r^{3}, 4.8$ \\
Sample temperature $\left({ }^{\circ}\right.$ C) & 25 & 25 & 25 \\
Sample pressure (torr) & 45 & 20 & 32 \\
Exposure time (sec) & 20 & 50 & 90 \\
Beam current $(\mu A)$ & 0.44 & 0.64 & 0.65 \\
Number of plates & 5 & 2 & 3 \\
\hline
\end{tabular}

University of Michigan [2], equipped with an $r^{3}$ sector, at camera distances of 20,10 and $6 \mathrm{~cm}$. Experimental conditions are given in Table 1*. Absorbances were converted to exposures following the procedure described elsewhere [3]. The intensity data for each distance were leveled after corrections had been made for extraneous scattering. Atomic scattering factors were taken from the work of Cox and Bonham [4] and Tavard, Nicolas and Rouault [5]. When the background functions for the three individual data sets had been established, they were blended to produce a composite set, interpolated in units of $\Delta s=\pi / 10$ which covered the range $4.1<s<41.5 \AA^{-1}$. Indices of resolution were $0.868,0.817$ and 0.831 for the 20,10 and $6 \mathrm{~cm}$ data, respectively. Diagonal weight matrices were used, whose elements were proportional to s; however, the uncertainties quoted have been augmented to include our estimates of the influence of correlation between neighboring data points [2], taking the correlation parameter $\gamma$ as $1 \AA$. Radial distribution functions were calculated using a damping function of $\exp \left(-0.0015 \mathrm{~s}^{2}\right)$. Asymmetry constants were taken to be 2.0 for bonded distances and 1.0 for non-bonded distances [6].

\section{VIBRATIONAL SPECTRUM AND FORCE FIELD}

It is by now well established that electron diffraction analyses of molecules containing non-symmetry-related distances of similar magnitude are subjective, to the extent that the amplitudes of vibration and geometrical parameters, which are often correlated, cannot both be determined by least-squares refinement procedures. This difficulty can be mitigated, and the reliability of the structure determination increased, if independent estimates are available of the amplitudes of vibration, for example from a calculation based on the molecular force field. While it is not possible, at least at present, to determine rigorously even the harmonic components of the force field of a molecule as

*The experimental leveled intensities and background functions for bis(trifluioromethyl)peroxide at camera distances of 20,10 and $6 \mathrm{~cm}$, together with the force conistantsused :in vibrational corrections, are ayailable as Sup. Pub; No: SUP26067 (10,päes) from-BLLD. 
complex as $\left(\mathrm{CF}_{3} \mathrm{O}\right)_{2}$, calculated amplitudes are not very sensitive to the many off-diagonal elements of the force field. We have previously developed [7] a valence force field which satisfactorily reproduced the observed vibrational spectra of $\mathrm{CF}_{3} \mathrm{OX}(\mathrm{X}=\mathrm{F}, \mathrm{Cl})$ and $\mathrm{CF}_{3} \mathrm{OOX}(\mathrm{X}=\mathrm{H}, \mathrm{F}, \mathrm{Cl})$, which we applied, with virtually no modification except for torsional elements, to $\mathrm{CF}_{3} \mathrm{OOCF}_{3}$.

The vibrational spectra of $\left(\mathrm{CF}_{3} \mathrm{O}\right)_{2}$ have been recorded and assigned by Durig and Wertz [1]. To the extent that shorthand labels such as "carbonoxygen stretching motion" can characterize the vibrations of a molecule of low symmetry all of whose atoms are similar in mass, the perceptive assignment of Durig and Wertz is largely confirmed by our calculations. We suggest, however, that the band observed at $1065 \mathrm{~cm}^{-1}$, assigned as the $B$ carbonoxygen stretching motion $\nu_{17}$ is not a fundamental, but a combination of $\nu_{8}$ $\left(627 \mathrm{~cm}^{-1}\right)$ and $\nu_{9}\left(445 \mathrm{~cm}^{-1}\right)$, and that $\nu_{17}$ is in fact the weak band seen at $933 \mathrm{~cm}^{-1}$.

Our force field, which is listed in the supplementary material, reproduced the observed frequencies with an average error of $2 \%$. From the point of view of the amplitudes of vibration and shrinkage corrections, however, the lowest frequencies are of the greatest importance, and unfortunately we were not able to fit this region satisfactorily. Durig and Wertz [1] observed three bands at less than $200 \mathrm{~cm}^{-1}$, namely 64,94 and $134 \mathrm{~cm}^{-1}$. These were assigned as the $A$ and $B$ combinations of the $\mathrm{CF}_{3}$ torsional motion, the $\mathrm{O}-\mathrm{O}$ torsional motion, and the $B \mathrm{C}-\mathrm{O}-\mathrm{O}-\mathrm{C}$ bending motion, respectively. Our calculations indicate that the $A \mathrm{CF}_{3}$ torsional mode is extensively mixed with the $\mathrm{O}-\mathrm{O}$ torsion, and that the $A$ and $B C_{3}$ torsions are not close in frequency. Using plausible torsional force constants, we calculated the $A \mathrm{CF}_{3}$ torsional motion to be near $64 \mathrm{~cm}^{-1}$, with the $B \mathrm{CF}_{3}$ torsion and the $\mathrm{O}-\mathrm{O}$ torsion both close to $94 \mathrm{~cm}^{-1}$. It was possible to fit the $\mathrm{O}-\mathrm{O}$ torsion to the band at $134 \mathrm{~cm}^{-1}$, but only by assuming a torsional force constant roughly as large as that in $\mathrm{F}_{2} \mathrm{O}_{2}$, in which the $\mathrm{O}-\mathrm{O}$ bond length is as short as in the $\mathrm{O}_{2}$ molecule. We were not able to fit a $\mathrm{C}-\mathrm{O}-\mathrm{O}-\mathrm{C}$ bending motion to the band at $134 \mathrm{~cm}^{-1}$; the modes best described as $\mathrm{C}-\mathrm{O}-\mathrm{O}-\mathrm{C}$ bends appear to be those at $228(A)$ and $211(B) \mathrm{cm}^{-1}$. These difficulties mean that the reliability of the calculated amplitudes and shrinkage corrections, listed in Table 2 , is uncertain, and we have accordingly augmented the uncertainties of the geometric parameters most affected by this uncertainty.

\section{STRUCTURE ANALYSIS}

Experimental and final calculated scattered molecular intensities are presented in Fig. 1, and the experimental radial distribution function in Fig. 2. It is evident that there are fewer distinct features in the radial distribution function than there are geometrical parameters to be determined. The three bonded distances all overlap; as do all the 1,3 non-bonded distances and most of the 1,4 distances. Although anticipating difficulty in extracting a unique best structure, we hoped that the availability of calculated amplitudes of vibration would eliminate the worst of the ambiguities. 
TABLE 2

Calculated amplitudes of vibration and shrinkage corrections for $\mathrm{CF}_{3} \mathrm{OOCF}_{3}$.Units are A

\begin{tabular}{|c|c|c|c|c|c|}
\hline Distance & Amplitude & Shrinkage & Distance & Aniplitüdé & Shrinkage \\
\hline $\begin{array}{l}C_{1}-F_{1} \\
C_{1}-O_{1} \\
O_{1}-O_{2} \\
F_{11} \cdots F_{12} \\
F_{11} \cdots O_{1} \\
F_{12} \cdots O_{1} \\
C_{1} \cdots O_{2} \\
F_{11} \cdots O_{1} \\
F_{12} \cdots O_{2} \\
C_{1} \cdots C_{2}\end{array}$ & $\begin{array}{l}0.045 \\
0.048 \\
0.051 \\
0.054 \\
0.062 \\
0.060 \\
0.064 \\
0.065 \\
0.118 \\
0.085\end{array}$ & $\begin{array}{l}0.0016 \\
0.0032 \\
0.0034 \\
0.0041 \\
0.0124 \\
0.0055 \\
0.0100\end{array}$ & $\begin{array}{l}F_{11} \cdots C_{2} \\
F_{12} \cdots C_{2} \\
F_{13} \cdots C_{2} \\
F_{11} \cdots F_{21} \\
F_{11} \cdots F_{22} \\
F_{11} \cdots F_{23} \\
F_{12} \cdots F_{22} \\
F_{12} \cdots F_{23} \\
F_{13} \cdots F_{23}\end{array}$ & $\begin{array}{l}0.099 \\
0.127 \\
0.149 \\
0.100 \\
0.19 \\
0.17 \\
0.21 \\
0.17 \\
0.115\end{array}$ & $\begin{array}{r}0.0179 \\
0.0164 \\
0.0072 \\
0.0307 \\
0.0151 \\
0.0195 \\
0.0085 \\
0.0207 \\
0.0244\end{array}$ \\
\hline
\end{tabular}

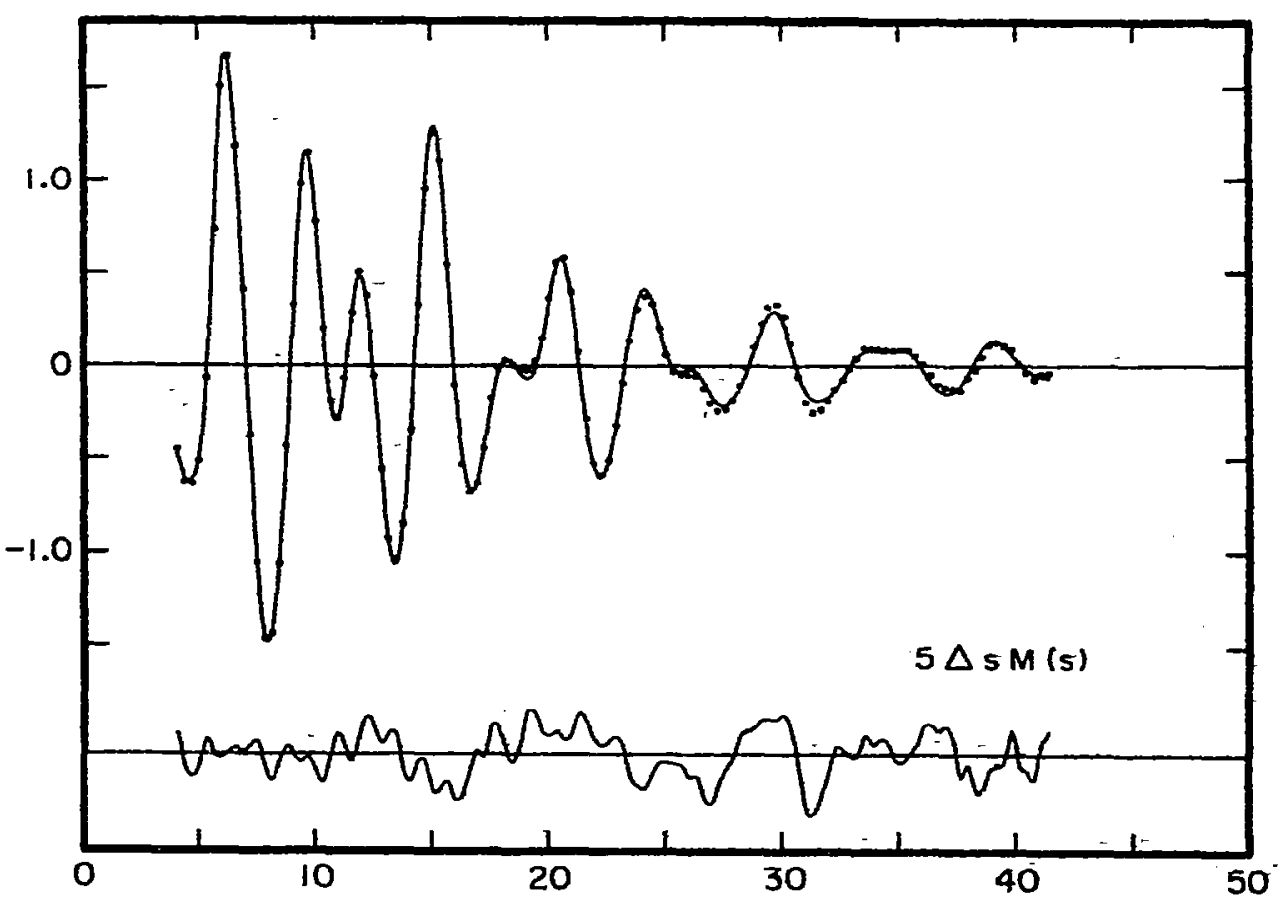

Fig. 1. Experimental (dots) and calculated (smooth curve) molecular intensity functions for $C F, O O C F,: \Delta s M(s)=\operatorname{sM}(\mathrm{s})$ expi $-\operatorname{si}(\mathrm{s}) \mathrm{calc}$

$A$ view of the molecule of $\mathrm{CF}_{3} \mathrm{OOCF}_{3}$, based on the final parameters, is given in Fig. 3. The model used imposed overall $C_{2}$ molecular symmety; and local $C_{3}$ symmetry upon the $\mathrm{CF}_{3}$ groups. These simplifications reduce to eight the number of geometrical parameters required to define the structure: We chose these to be the $O=0, C-0$ aria? $C-F b$ ond length the $C-0=0$ bond angle, the angle between a $C-F$ bond and the adjacent $C$ bond an 


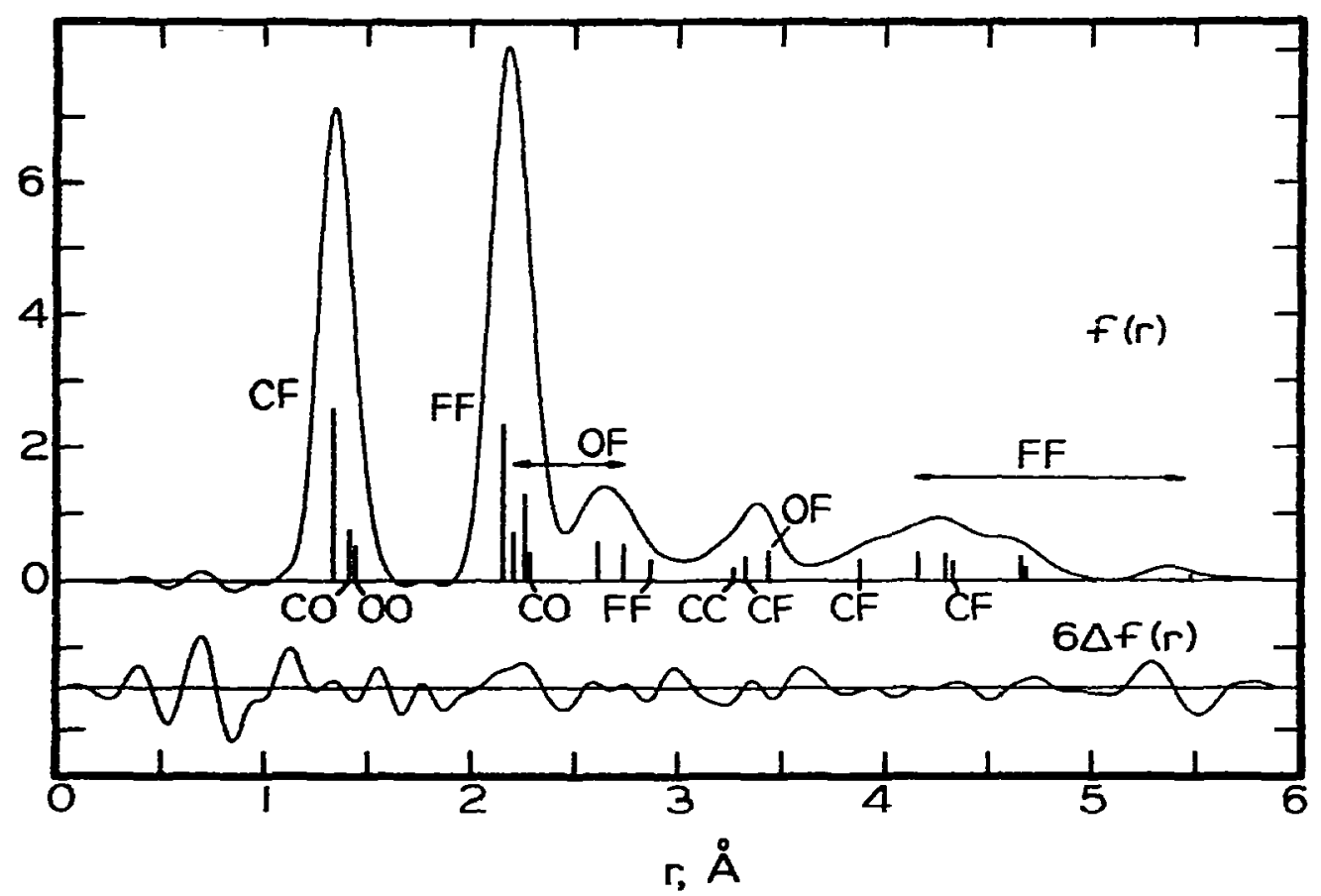

Fig. 2. Experimental radial distribution function for $\mathrm{CF}_{3} O O C F_{3}: \Delta f(r)=f(r)_{\text {expt }}-f(r)_{\text {calc }}$.

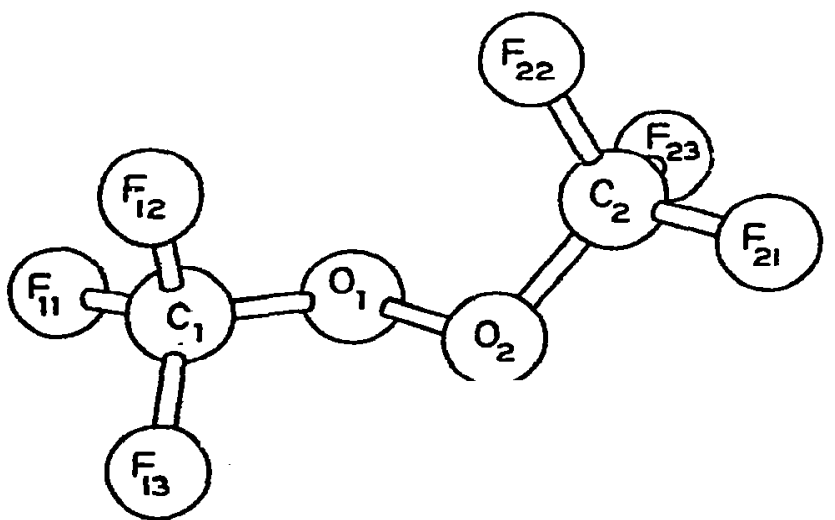

Fig. 3. A perspective view of the molecule $\mathrm{CF}_{3} \mathrm{OOCF}$, showing the atom labeling scheme.

angle $a$ describing the tilt of the $\mathrm{CF}_{3}$ groups, the $\mathrm{C}-\mathrm{O}-\mathrm{O}-\mathrm{C}$ dihedral angle, and a twist angle $\beta$ defining the conformation of the $\mathrm{CF}_{3}$ groups. A non-zero value of $\alpha$ indicates that the $C_{3}$ axis of the $\mathrm{CF}_{3}$ group is not colinear with the $C-O$ bond, but lies in the $\mathrm{CO}_{1} \mathrm{O}_{2}$ plane; such that $\mathrm{F}_{11}$ is closer to $\mathrm{O}_{1}$ than are $F_{12}$ or $F_{i 3}$ if $\alpha$ is positive. The angle $\beta$ measures the rotation of the $C F_{3}$ groups about their $C_{3}$ axes away from the staggered conformation for which $\beta$ is zero. 
A positive value of $\beta$ rotates $F_{12}$ closer to $O_{2}$ (and $F_{22}$ closer to $O_{1}$ ) and $F_{13}$ away from $\mathrm{O}_{2}$.

Prior to refining the structure by least squares, preliminary calculations were made of the non-bonded distances, assuming bond lengths and angles similar to those reported for $\mathrm{CF}_{3} \mathrm{OF}$ and $\mathrm{CF}_{3} \mathrm{OOX}(\mathrm{X}=\mathrm{H}, \mathrm{F}, \mathrm{Cl})$. It was found that if the $\mathrm{C}-\mathrm{O}-\mathrm{O}-\mathrm{C}$ dihedral angle was near $90^{\circ}$, and the $\mathrm{CF}_{3}$ groups close to staggered, then the $F_{12} \cdots F_{22}$ distances would be in the region of $2 \AA$. Such a value appeared improbably small in view of the accepted van der Waals radius for fluorine of $1.35 \AA$. Several least-squares refinements were made, starting from widely differing initial parameter values, and three minima were found. While the structures of a $\mathrm{CF}_{3} \mathrm{O}$ grouping were essentially the same in all three minima, the $\mathrm{C}-\mathrm{O}-\mathrm{O}-\mathrm{C}$ dihedral angle and angle of twist $\beta$ were quite different. Minimum I was characterized by a large dihedral angle of roughly $125^{\circ}$, with approximately staggered $\mathrm{CF}_{3}$ groups. The angle $\beta$ was also near zero in minimum II, for which the dihedral angle was near $90^{\circ}$, but minimum III possessed approximately eclipsed $\mathrm{CF}_{3}$ groups and a dihedral angle in the region of $80^{\circ}$. Standard deviations of the diffraction intensity data for minima I, II, and III were roughly in the ratio 1:2:3. Although the amplitudes of vibration for minima II and III were not extensively optimized, we consider that the quality of the fit provided by minimum I was so superior to that of the other two that they can unhesitatingly be rejected as spurious. It should be noted that all three minima gave qualitatively acceptable fits to the intensity data, an observation which underlines the importance of investigating a range of different models in cases where parameter correlation may be expected.

Four amplitudes of vibration were refined in the final cycles, and their values are acceptably close to those calculated from the approximate force field discussed above. We did not find it profitable to free amplitudes for any extra distances. Although such refinements did converge satisfactorily and the resulting amplitudes were not greatly different from those calculated spectroscopically, their uncertainties were very large, resulting from their correlation with certain geometrical parameters. A set of refinements was performed in which the two $\mathrm{CF}_{3}$ groups were allowed independent angles of twist, thereby slightly relaxing the constraint of overall $C_{2}$ symmetry. The resulting improvement in fit to the intensity data was extremely modest, and the values of $\beta$ obtained of $-2^{\circ}$ and $-10^{\circ}$ did not appear to us to be significantly different.

Final parameter values are presented in Table 3; the uncertainties listed are $3 \sigma$, and include not only random errors, but also our estimates of systematic errors, the effects of correlation between neighboring data points. and the uncertainties introduced by the ambiguities in assigning torsional modes discussed above. Several moderately large elements may be seen in the correlation matrix, displayed in Table 4 . 
TABLE 3

Structural parameters for $\mathrm{CF}_{3} \mathrm{OOCF}$,

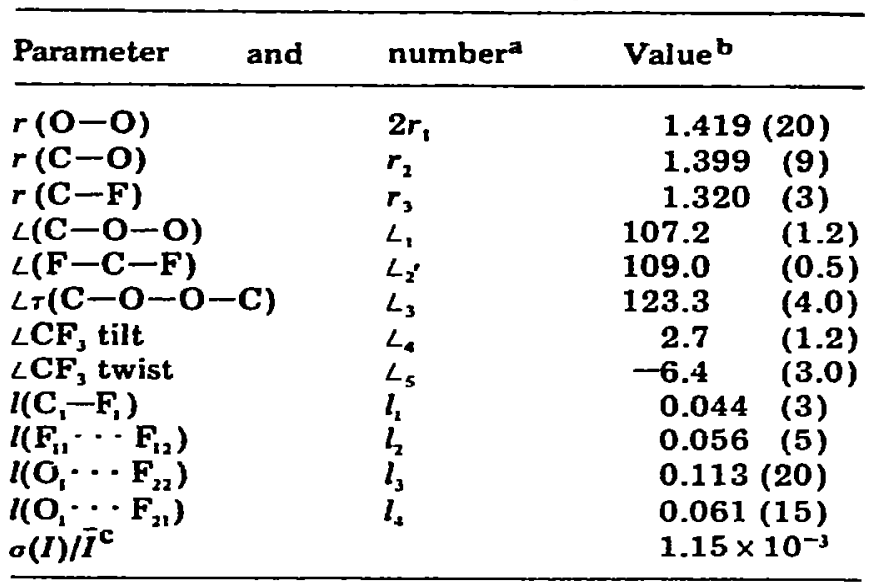

"See text for definition of tilt and twist angles.

b Bond lengths are $r_{\mathrm{g}}$, amplitudes are $l_{\mathrm{g}}$. Units for bond lengths and amplitudes are $\mathrm{A}$, for angles are degrees. Uncertainties, given in units of the least significant digit, are $3 \sigma$, and include random and suspected systematic errors, and our estimates of the effects of correlation between neighboring data points and the uncertainties in the calculated amplitudes of vibration and shrinkage corrections.

c Mean fractional standard deviation of diffraction intensity data.

\section{DISCUSSION}

Several studies have been made of systems of the type $X_{n} A_{n}$, in which $A$ is a main group element. It appears that $A-A$ bonds are shorter if $X=C_{3}$ than if $\mathrm{X}=\mathrm{H}$ or $\mathrm{CH}_{3}$. We may quote the examples of $\mathrm{P}_{2}\left(\mathrm{CF}_{3}\right)_{4}$ [8] and $\mathrm{P}_{2} \mathrm{H}_{4}[9]$, in which the $P-P$ bond lengths are 2.182(8) and 2.219(1) $\AA$ respectively, the Se-Se distances in $\mathrm{Se}_{2}\left(\mathrm{CF}_{3}\right)_{2}$ [10] and $\mathrm{Se}_{2}\left(\mathrm{CH}_{3}\right)_{2}$ [11] of 2.292(10) and 2.326(2) $\AA$, and the bond lengths of 1.40(2) $\AA$ in $N_{2}\left(C_{3}\right)_{4}$ [12] and 1.449(4) $\AA$ in $\mathrm{N}_{2} \mathrm{H}_{4}$ [13]. Although the $\mathrm{O}-\mathrm{O}$ distance in gaseous $\mathrm{H}_{2} \mathrm{O}_{2}$ is rather uncertain, it appears to be appreciably longer than that in $\mathrm{CF}_{3} \mathrm{OOCF}_{3}$. Values of 1.475(4) \& [14] and 1.452(4) \& [15] have been derived for the $O-O$ separation in $\mathrm{H}_{2} \mathrm{O}_{2}$ from the measurements of the rotational constants; a bond length of 1.453(7) $\AA$ determined in a neutron diffraction study [16] of crystalline $\mathrm{H}_{2} \mathrm{O}_{2}$ would be increased by up to several hundredths of an Angstrom unit if motional corrections were made. We have found the $\mathrm{O}-\mathrm{O}$ distance in gaseous $\mathrm{CF}_{3} \mathrm{OOCF}_{3}$ to be 1.419(7) \& (10). A recent electron diffraction investigation of $\mathrm{t}-\mathrm{BuOO} t-\mathrm{Bu}$ has reported the $\mathrm{O}-\mathrm{O}$ bond length to be $1.480 \mathrm{~A}$ [17]. It seems possible that repulsions between nonbonding electrons on $A$ atoms are important in these systems; electronwithdrawing groups such as $\mathrm{CF}_{3}$ could be expected to reduce their influence, 


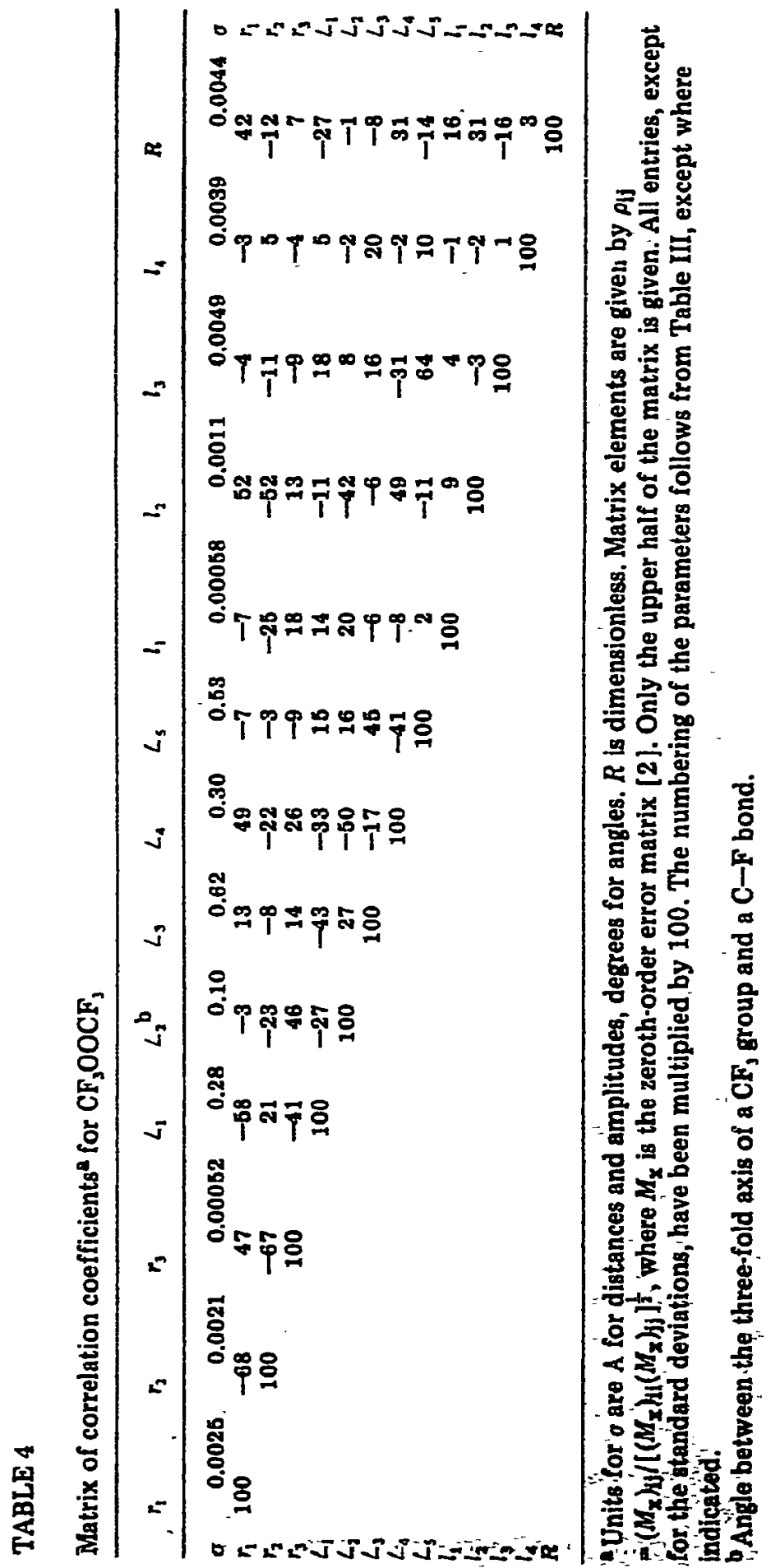


leading to shorter $\mathbf{A}-\mathbf{A}$ bonds. If this were the only factor involved, however, one might anticipate a much shorter $P-P$ bond in $P_{2} F_{4}$ than is in fact observed [18].

The $\mathrm{C}-\mathrm{O}$ bond length of $\mathbf{1 . 3 9 9 ( 3 ) ~} \AA$ in $\mathrm{CF}_{3} \mathrm{OOCF}_{3}$ is appreciably shorter than those in $\mathrm{CH}_{3} \mathrm{OH}$ [18] or $\mathrm{t}-\mathrm{BuOOt}-\mathrm{Bu}$ [17], [1.428(3) and 1.460(9) $\AA$, respectively] but comparable to those in $\mathrm{CF}_{3} \mathrm{OF}[1.395(6) \AA], \mathrm{CF}_{3} \mathrm{OOH}$ [19] [1.376(3) $\AA]$, and $\mathrm{CF}_{3} \mathrm{OOCl}$ [19] [1.372(7) $\AA$ ]. It is generally found [10] that $\left(\mathrm{F}_{3}\right) \mathrm{C}-\mathrm{X}$ bonds are shorter than analogous $\left(\mathrm{H}_{3}\right) \mathrm{C}-\mathrm{X}$ bonds if $\mathrm{X}$ is highly electronegative, such as $\mathrm{F}, \mathrm{O}$ or $\mathrm{Cl}$, but longer if $\mathrm{X}$ is of moderate electronegativity, for example $\mathbf{P}$ or Se. This phenomenon is discussed elsewhere [20].

In a recent study of the structures of $\mathrm{CF}_{3} \mathrm{OOX}$ [19], it was found that the barriers to torsional motion about the $\mathrm{O}-\mathrm{O}$ bonds in $\mathrm{CF}_{3} \mathrm{OOH}, \mathrm{CF}_{3} \mathrm{OOF}$, and FOOF were correlated with the $\mathrm{O}-\mathrm{O}$ bond lengths in these molecules. (The barrier height in $\mathrm{CF}_{3} \mathrm{OOCl}$ has not been determined.) Although the low frequency vibrational spectra of $\mathrm{CF}_{3} \mathrm{OOCF}_{3}$ do not permit an unambiguous assignment of the $\mathrm{O}-\mathrm{O}$ torsional mode, it appears that the barrier height in this molecule may be similar to that in $\mathrm{CF}_{3} \mathrm{OOF}$ [19], in which the $\mathrm{O}-\mathrm{O}$ bond length is $1.366(11) \AA$. If the relationship between bond length and barrier for $\mathrm{CF}_{3} \mathrm{OOH}, \mathrm{CF}_{3} \mathrm{OOF}$, and $\mathrm{FOOF}$ has any validity, it seems that the barrier in $\mathrm{CF}_{3} \mathrm{OOCF}_{3}$ is anomalously high. A high barrier could readily be rationalized by the unfavorable $F$ - . F interactions produced by torsional action about the $\mathrm{O}-\mathrm{O}$ bond; indeed, evidence that such unfavorable interactions are present in the equilibrium conformation of the molecule is provided by the large $\mathrm{C}-\mathrm{O}-\mathrm{O}-\mathrm{C}$ dihedral angle of $123.3\left(1.3^{\circ}\right)$ in $\mathrm{CF}_{3} \mathrm{OOCF}_{3}$, whereas dihedral angles in disubstituted Group VI derivatives are generally $[21,11]$ in the range $85-100^{\circ}$. Even though a plausible expression for F ... F interaction potentials is available [22], it is unfortunately not simple to calculate the steric component of the $\mathrm{O}-\mathrm{O}$ torsional barrier without taking carefully into account how the other geometrical parameters, in particular the $\mathrm{CF}_{3}$ twist angle, relax as the $\mathrm{C}-\mathrm{O}-\mathrm{O}-\mathrm{C}$ dihedral angle is changed. The very large dihedral angle of $165.8\left(2.4^{\circ}\right)$ reported for $t-B u O O t-B u$ [17] may be taken as an indication that steric problems are more acute in that molecule than in $\mathrm{CF}_{3} \mathrm{OOCF}_{3}$. Taken together with the present study, an analysis of the conformational behavior of bis(trifluoromethyl)peroxide by the rapidly developing technique of "molecular mechanics" [23, 24] might provide helpful information about magnitudes of interactions between $\mathrm{CF}_{3}$ groups.

\section{ACKNOWLEDGEMENTS}

This research was supported by a grant from the National Science Foundation. We gratefully acknowledge a fellowship (F. P. D.) from Consejo Nacional de Investigaciones Cientificas y Técnicas, República Argentina, during the tenure of which the experimental work was carried out. We are indebted to Mr. S. E. Woehler for assistance in some of the computations. 


\section{REFERENCES}

1 J. R. Durig and D. W. Wertz, J. Mol. Spectrosc., 25 (1968) 467.

2 L. S. Bartell, in A. Weissberger and B. W. Rossiter (Eds.), Physical Methods in Chemistry, 4th.edn., Intêrscience, New York, 1973.

3 F. P. Diodati and L.S. Bartell, J. Mol. Struct., 8 (1971) 395.

4 H. L. Cox and R. A. Bonham, J. Chem. Phys., 47 (1967) 2599.

5 C. Tavard, D. Nicolas and M. Rouault, J. Chem. Phys., 64 (1967) 540.

6 L. S. Bartell, J. Chem. Phys., 23 (1955) 1219.

7 R. Hammaker and C. J. Marsden, unpublished research, 1976.

8 H. L. Hodgés, L. S. Su and L. S. Bartell, Inorg. Chem., 14 (1975) 599.

9 J. R. Durig, L. A. Carreira and J. D. Odom, J. Am. Chem. Soc., 96 (1974) 2688.

10 C. J. Marsden and G. M. Sheldrick, J. Mol. Struct., 10 (1971) 419.

11 P. D'Antonio, C. George, A: H. Lowrey and J. Karle; J. Chem. Phys., 55 (1971) 1071.

12 L. S. Bartell and H. K. Higginbotham, Inorg. Chem., 4 (1965) 1346.

13 Y. Morino, T:Iijima and Y. Murata, Bull. Chem. Soc. Jpn., 33 (1960) 46.

14 R. L. Redington, W. B. Olson and P. C. Cross, J. Chem. Phys., 36 (1962) 1311.

15 G. A. Khachkuruzov and I. N. Przheralskii, Opt. Spectrose., 36 (1974) 172.

16 W. R. Busing and H. A. Levy, J. Chem. Phys.; 42 (1965) 3054.

17 D. Käss and H. Oberhammer, Proceedings of Sixth Austin Symposium on Gas Phase Molecular Siructure, (1976) A91.

$18 \mathrm{~K}$. Kimura and M. Kubo, J. Chem. Phys., 30 (1959) 151.

19 C. J. Marsden, D. D. DesMarteau and L. S, Bartell, "An Electron Diffraction Investigation of $\mathrm{CF}_{3} \mathrm{OOH}, \mathrm{CF}_{3} \mathrm{OOF}$ and $\mathrm{CF}_{3} \mathrm{OOCl}$ ", submitted to Inorg. Chem.

20 C. J. Marsden and L. S. Bartell, Inorg. Chem., 15 (1976) 2713.

21 R. Rothman, S: Safe and A. Taylor, Quart. Rev. Chem. Soc., 24 (1970) 208.

22 L. S. Bartell and S. E. Wohler, unpublished research, 1976.

23 S. Fitzwater and L. S. Bartell, J. Am. Chem. Soc., 98 (1976) 5107.

24 N. L. Allinger, Symposium on Non-Bonded Interactions, Centennial Meeting, American Chemical Society, San Francisco: August, 1976. 